\title{
Sustained unresponsiveness to peanut in subjects who have completed peanut oral immunotherapy
}

\author{
Brian P. Vickery, MD1, Amy M. Scurlock, MD², Michael Kulis, PhD ${ }^{1}$, Pamela H. Steele, \\ CPNP $^{1}$, Janet Kamilaris, RN ${ }^{1}$, Jelena P. Berglund, PhD $^{3}$, Caitlin Burk, BA ${ }^{1}$, Anne Hiegel, \\ $\mathbf{R N}^{2}$, Suzanna Carlisle, RN², Lynn Christie, RD ${ }^{2}$, Tamara T. Perry, $\mathbf{M D}^{2}$, Robbie D. Pesek, \\ MD², Saira Sheikh, MD ${ }^{1}$, Yamini Virkud, MD, MA ${ }^{4}$, P. Brian Smith, MD, MHS, MPH ${ }^{4}$, \\ Mohamed H. Shamji, MD ${ }^{5}$, Stephen R. Durham, MD $^{5}$, Stacie M. Jones, MD ${ }^{2}$, and A. Wesley \\ Burks, MD ${ }^{1}$ \\ ${ }^{1}$ Department of Pediatrics, University of North Carolina School of Medicine, Chapel Hill, NC \\ ${ }^{2}$ Department of Pediatrics, University of Arkansas for Medical Sciences and Arkansas Children's \\ Hospital, Little Rock, AR \\ ${ }^{3}$ Duke Translational Medicine Institute, Durham, NC \\ ${ }^{4}$ Department of Pediatrics, Duke University School of Medicine, Durham, NC \\ ${ }^{5}$ Imperial College, London UK
}

\begin{abstract}
Background-Although peanut oral immunotherapy (OIT) has been conclusively shown to cause desensitization, it is currently unknown whether clinical protection persists after stopping therapy.

Objective-Our primary objective was to determine whether peanut OIT can induce sustained unresponsiveness following withdrawal of OIT.

Methods-We conducted a pilot clinical trial of peanut OIT at two U.S. centers. Subjects aged 1-16 were recruited and treated for up to five years with peanut OIT. The protocol was modified over time to permit dose increases to a maximum of $4000 \mathrm{mg}$ peanut protein/day. Blood was collected at multiple time points. Clinical endpoints were measured with $5000 \mathrm{mg}$ double-blinded, placebo-controlled food challenges once specific criteria were met.
\end{abstract}

Results-Of the 39 subjects originally enrolled, 24 completed the protocol and had evaluable outcomes. 12/24 (50\%) successfully passed a challenge one month after stopping OIT and achieved sustained unresponsiveness. Peanut was added to the diet. At baseline and the time of challenge, such subjects had smaller skin tests as well as lower IgE levels specific for peanut, Ara $\mathrm{h} 1$, and Ara h 2, and lower ratios of peanut-specific:total IgE, compared to subjects not passing. There were no differences in peanut IgG4 levels or functional activity at end-of-study.

Conclusions-This is the first demonstration of sustained unresponsiveness after peanut OIT, occurring in half of subjects treated up to five years. OIT favorably modified the peanut-specific

(C) 2013 American Academy of Allergy, Asthma and Immunology. Published by Mosby, Inc. All rights reserved.

Corresponding Author: Brian P. Vickery, MD, CB\#7231, Genome Sciences Building, Bell Tower Drive, Chapel Hill, NC 27599; bvickery@email.unc.edu; (919) 962-4400 (phone); (919) 962-5136 (fax).

Publisher's Disclaimer: This is a PDF file of an unedited manuscript that has been accepted for publication. As a service to our customers we are providing this early version of the manuscript. The manuscript will undergo copyediting, typesetting, and review of the resulting proof before it is published in its final citable form. Please note that during the production process errors may be discovered which could affect the content, and all legal disclaimers that apply to the journal pertain. 
immune response in all subjects completing the protocol. Smaller skin tests and lower allergenspecific IgE levels were predictive of successful outcome.

\section{Keywords}

Peanut allergy; Oral immunotherapy; Desensitization; Tolerance; Sustained Unresponsiveness

\section{INTRODUCTION}

Food allergy is the leading cause of anaphylaxis in children, and in the last 20 years it has become an increasingly prevalent public health problem with adverse medical, psychosocial and economic effects. (1-5) This is especially true for peanut allergy, which carries a high risk of severe reactions $(6,7)$ and is typically a life-long disorder. $(8,9)$ Presently, the standard of care for food allergy is strict dietary allergen elimination and ready access to emergency medications. Consensus NIH guidelines recommend against the current use of interventional therapies. (2)

However, recent trials of oral immunotherapy (OIT) have demonstrated progress toward an active treatment approach for food allergy. (10-15) In a preliminary report from an uncontrolled pilot study of peanut OIT in children, our group demonstrated that successful clinical desensitization occurred in 27/29 (93\%) of subjects completing more than eight months of therapy and was associated with relevant mechanistic changes in the peanutspecific immune response. (13) Subsequently, a randomized placebo-controlled trial conclusively demonstrated desensitization and immunomodulation, validating the pilot work and supporting the efficacy of OIT in peanut allergy. (15) Other mechanistic studies have shown that peanut OIT complexly modifies the IgE and IgG4 responses to the linear epitopes from the major peanut allergens Ara h 1,2, and 3, (16) and induces basophil hyporesponsiveness during treatment. (17) Collectively, these results support the idea that the immunomodulatory effects of OIT are similar to accepted forms of immunotherapy that have been proven to be disease-modifying in venom anaphylaxis and respiratory allergy. $(18-20)$

Yet only one trial to date has conclusively demonstrated that OIT is disease-modifying, using egg white powder in egg-allergic subjects. (21) The term "sustained unresponsiveness" was introduced in this landmark study, describing the ability of a subject to pass an oral food challenge (OFC) after stopping OIT and successfully introduce a previously allergenic food into the diet ad libitum. Whereas egg allergy is commonly outgrown, this is uncommon for peanut allergy, and sustained unresponsiveness to peanut has not previously been shown.

We sought to determine, in the same peanut-allergic cohort in whom desensitization was previously reported, (13) whether long-term treatment with OIT would result in sustained unresponsiveness to peanut, and to identify the clinical and immunologic parameters associated with this state.

\section{METHODS}

\section{Subject Recruitment}

This trial was conducted in accordance with the principles of the Declaration of Helsinki. Ethics approval was obtained through the Institutional Review Boards at Duke University Medical Center and University of Arkansas for Medical Sciences (UAMS). Written informed consent was obtained prior to study participation in accordance with each institution's ethics guidelines for research in children. Subjects, ages 1 to 16 years, were 
recruited from the allergy and immunology clinics or surrounding community physician offices at both sites. An interim analysis of this cohort of subjects was previously published; (13) the end-of-study results of the same clinical trial are presented here.

\section{OIT Protocol}

Details of subject selection and the peanut OIT protocol have been previously published, (13) and are available in the supplemental methods section online. Briefly, OIT was administered in an open-label fashion to peanut-allergic subjects daily in three phases: initial day escalation, build-up, and maintenance, which continued until subjects met eligibility for endpoint assessment as described below. For the duration of the study, subjects strictly avoided all peanut except for that provided in the dose of their study product.

\section{Clinical Endpoints}

Subjects in this study underwent at least three OFCs. The first, which was previously reported, (13) was an open OFC to $3900 \mathrm{mg}$ of peanut protein conducted shortly after reaching the maintenance dose. In the current study, qualifying subjects from the previous report were evaluated with two double-blinded, placebo-controlled food challenges (DBPCFC) to a total of $5000 \mathrm{mg}$ of peanut protein, performed four weeks apart. Details of these challenges have been previously published. (15) The first of these challenges (referred to in the Figures as "Desensitization OFC," or DOFC) was performed to assess reactivity while on treatment, and OIT was stopped if this DBPCFC was passed. The next challenge (referred to in the Figures as "Sustained Unresponsiveness OFC", or SOFC) was conducted four weeks after stopping OIT and assessed the primary endpoint called sustained unresponsiveness, which we operationally defined as the ability to asymptomatically consume all of the challenge material and then an open oral feeding of one serving (e.g. $8000-10,000 \mathrm{mg}$ ) of peanut butter afterward on the same day. Subjects passing the SOFC were classified as treatment successes (TS) and those developing convincing allergic symptoms during their final SOFC or open feeding were classified as treatment failures (TF). The criteria for the timing of the assessment of sustained unresponsiveness varied as the study progressed. The initial protocol called for SOFC once peanut IgE levels were $<2$ $\mathrm{kU} / \mathrm{L}$. We subsequently amended the protocol to offer SOFCs to subjects with a peanut IgE $<15 \mathrm{kU} / \mathrm{L}$, peanut SPT $<5 \mathrm{~mm}$, and no peanut-related reactions in the previous six months. Because of the exploratory nature of this pilot study, if subjects failed the SOFC during these first two phases of evaluation, they resumed OIT. The final phase of assessment for sustained unresponsiveness occurred in all remaining subjects, who underwent SOFC at the completion of five years of OIT, regardless of their immune parameters. TS were advised to incorporate peanut into the diet ad libitum at least several days per week. The day after the final SOFC, TF were restarted on a predetermined amount of a peanut-containing food daily and are being followed.

\section{Clinical and Mechanistic Studies}

Skin prick tests were performed in standard clinical fashion throughout the study. Mechanistic studies investigating serological and cellular responses to OIT, and utilizing purified peanut reagents, were performed as previously described (13) on the subjects enrolled at one of the study sites, due to the availability of specimens there. Additional details about these assays may be found in the supplementary material online.

\section{Follow-up}

A ten-question telephone survey was developed to assess post-OIT dietary habits, safety, and beliefs/attitudes after study completion. Contact was attempted with all subjects who 
had an evaluable outcome. The questionnaire is available in the supplementary material online.

\section{Statistical Methods}

We computed averages, variances, frequencies, proportions, and graphical displays for all clinical and immunologic variables (GraphPad, La Jolla, CA). We used Wilcoxon rank sum and Mann-Whitney tests for between-group comparisons of immunologic and FAB data, respectively, at single time points. Kruskal-Wallis and Fisher's Exact tests were used for between-group comparisons of questionnaire data. For longitudinal analyses, we used Bonferroni-corrected nonparametric two-way repeated measures ANOVA or simple linear regression. The area under the receiver operating curve was calculated to determine between-group predictors. P-values $<0.05$ were considered significant.

\section{RESULTS}

\section{Subject demographics}

39 subjects were originally enrolled in the trial, and ultimately $24(62 \%)$ had an evaluable outcome with respect to sustained unresponsiveness (Figure 1). 6/39 (15\%) of enrolled subjects withdrew for allergic side effects; the remaining nine were for personal or other reasons. Clinical and demographic characteristics of the 24 evaluated subjects were no different than those of the subjects withdrawing (not shown). As previously noted, subjects in this study were not evaluated for sustained unresponsiveness at the same time interval, with a mean (SD) length of treatment of 1453 (663) days.

\section{Half of finishing subjects achieved sustained unresponsiveness}

Twelve TS subjects ( $50 \%$ per protocol; or $31 \%$ by intent-to-treat) consumed $5000 \mathrm{mg}$ of peanut protein and an open oral feeding of peanut butter without symptoms four weeks after stopping OIT and were considered to have achieved sustained unresponsiveness (Figure 2). Among TF, the median (range) amount of peanut protein ingested cumulatively prior to the development of symptoms was 3750 (1500-5000) mg, equivalent to approximately 12 peanuts on average.

\section{Sustained unresponsiveness was inversely associated with skin test reactivity at baseline and end-of-study}

At baseline, TS had smaller skin tests than TF (median $9 \mathrm{~mm}$ versus $14 \mathrm{~mm}$, respectively; $\mathrm{p}=0.02$ ) (Figure 3A). During treatment in all subjects, OIT suppressed mast cell responsiveness, as demonstrated by a reduction in mean wheal diameter in skin prick tests obtained at baseline and at the time of the DOFC. This suppression persisted in TS upon discontinuation of OIT, whereas in TF, wheal diameters returned to near-baseline levels (Figure 3B).

\section{Intensity of allergic priming was inversely related to sustained unresponsiveness}

Compared to TF at baseline and at every subsequent time point measured, TS had lower median IgE levels specific for peanut, Ara h 1, and Ara h 2 (Figures 4A and 4B). The total amount of IgE was not different between groups (not shown). Importantly, all subjects on OIT experienced a longitudinal reduction to below baseline levels for some (peanut, Ara h 1, 2,3 ) but not all (Ara h 8,9) allergen-specific IgE. (Figure 4C) All subjects experienced a reduction in the ratio of peanut-specific to total IgE (Figure 4D), and this ratio was lower at baseline and at end-of-study in TS as compared to TF (Figure 4E). 


\section{Sustained unresponsiveness was not associated with the amount or inhibitory capacity of peanut-specific IgG}

Peanut-specific IgG, including IgG4, increased in all subjects (Figure 5A). During the first year, a striking increase occurred in the total amount of peanut-specific IgG of subtypes other than IgG4. This production peaked at about 12 months of therapy and then dropped, reaching a steady-state at around 18 months; in contrast, IgG4 production steadily increased over time. The amount of peanut-specific IgG4 was not associated with clinical outcome at baseline or at end-of-study (Figure 5B). The ratio of peanut-specific IgE to IgG4 steadily declined over the course of therapy (Figure 5C), and was significantly different between groups at baseline and at end-of-study (Figure 5D). Figure 6A shows the inhibitory capacity of $\operatorname{IgG}$ in a subset $(\mathrm{N}=14)$ of subjects, demonstrating considerable variance but an overall increase in the inhibitory activity of subjects' sera over time [slope -0.49 (95\%CI, -0.78 to $-0.19), p=0.002]$. Unexpectedly, there was a trend towards TS sera having lower inhibitory function than TF, which was statistically significant at 12 months but not at time of challenge (Figure 6B).

\section{Sustained unresponsiveness was not associated with the number of regulatory $T$ cells at SOFC}

There were no between-group differences in the proportion of CD4+CD25+FOXP3+ T cells at end-of-study, in a subset of subjects for whom sufficient cells were available (Figure E1).

\section{Predictors of sustained unresponsiveness}

We determined with ROC analysis whether readily available parameters could discriminate between TS and TF at baseline and end-of-study. At baseline, the strongest predictor was the ratio of peanut-specific:total IgE (Figure E2) [AUC=0.96; $\mathrm{p}=0.005$ ], whereas at end-ofstudy, it was Ara h 2-specific IgE (Figure E3) [AUC=0.9; $\mathrm{p}=0.003$ ]. Notably, the secondbest predictor in both baseline and end-of-study parameters was peanut-specific IgE. Peanutspecific IgG4 had no discriminatory power at either time point.

\section{Successes consume peanut without symptoms after stopping OIT}

Questionnaire response was $87.5 \%(\mathrm{n}=21)$. The median (range) time to follow-up after the SOFC in the TF group was 12 (3-36) months and 40 (3-56) months among TS. None of TS reported allergic reactions associated with peanut exposure, whereas three (14\%) TF reported mild peanut reactions, none of which required epinephrine or a physician visit. TS incorporated a median $555(0-4000) \mathrm{mg} /$ day of peanut protein into the diet on average three (0-7) days/week. This was less frequent compared to TF, who incorporated a median 895 (330-4000) $\mathrm{mg} /$ day, seven (5-7) days/week [ $\mathrm{p}=0.0003$ for frequency comparison]. The longest median interval in days between peanut exposures was greater in TS (14, range 2 to $>365)$ than in TF $(2,0-7)$ [p=0.004]. One of the TS stopped taking peanut in the diet due to personal, not medical, considerations; and over the subsequent year, we observed significant increases in his skin test size $(0.5 \mathrm{~mm}$ to $16 \mathrm{~mm})$ and in vitro IgE levels (3.56 kU/L to 11.5$)$. We have advised him to continue peanut avoidance. Fifty-seven percent of parents encountered some difficulty in getting their child to willingly consume peanut in their diets, with nineteen percent each reporting difficulty "about half of the time," and "every time;" these frequencies were not different between TS and TF. All surveyed families reported satisfaction with their decision to participate in the study; their post-study narrative comments appear in Table E1. 


\section{DISCUSSION}

Here we report on the end-of-study results of our initial pilot trial of peanut OIT, providing an update from our previously published interim report. (13) After a maximum of five years and $4000 \mathrm{mg} /$ day of OIT, all subjects completing the study successfully ingested $5000 \mathrm{mg}$ of peanut protein without symptoms during the DOFC and were considered desensitized. Fifty percent of these individuals successfully repeated this challenge one month after stopping OIT and demonstrated sustained unresponsiveness. This trial lacked the placebo control required for definitive proof, but based on natural history studies, $(8,9,22)$ it is highly unlikely that half of the study population would have outgrown peanut allergy during this study period. Thus these data represent the first descriptions of a lasting state of sustained unresponsiveness among peanut-allergic children treated with OIT and serve as proof of concept that such an outcome is possible. We advised successful subjects to incorporate peanut into their diet on a regular basis without restriction as if they were no longer allergic. A relapse appears likely in the one successful subject described above who could not do this. However, despite reporting that it was frequently difficult, all of the other TS now regularly do consume relatively small amounts of peanut, to which they were previously highly allergic. It is not known at present whether this clinical change is permanent, but notably we have a median of over 40 months' follow-up. The ability of OIT trial participants, even those classified as successes, to reintroduce allergen into the diet long term after study completion has been questioned (23), and it appears this may be necessary to prevent relapse in some subjects, as we observed. Although we report a substantially higher proportion of dietary adherence than Keet et al. over a longer period of follow-up, we share the concern that a need for ongoing regular oral exposure during and after therapy may be a potential limitation of this approach and an area that requires much more study.

Interestingly, among $\mathrm{TF}$, a median cumulative $3750 \mathrm{mg}$ was required to elicit symptoms during the SOFC. This eliciting dose is several orders of magnitude greater than at baseline, when, although not formally challenged, all subjects had clinical reactions prior to reaching the $50 \mathrm{mg}$ dose on the initial escalation day. (13) Thus, even in participants not achieving the primary outcome, OIT still induced a state of altered reactivity between peanut allergy and sustained unresponsiveness. One possible explanation is that among TF, who all passed the DOFC and were considered desensitized, the protective effects of OIT began to subside during the four weeks off of therapy. As was seen in another short peanut OIT trial, (14) clinical reactivity in the post-treatment OFC was linked to the return of peanut-induced mast cell activation. Other studies of egg, milk, and peanut OIT have also shown that the clinical desensitization effect was transient, in some cases within one or two weeks after discontinuing OIT. $(11,14,25)$ However, as in this study, the reaction threshold in all subjects from both of these studies remained well above their baseline. Of note, subjects in the current study were treated for up to five years, the longest trial of peanut OIT published to date, and far longer than the studies cited above. This could help explain the overall success rate and also the high eliciting dose during the SOFC among TF. Based on other OIT studies and the broad experience with subcutaneous allergen immunotherapy, it is likely that the length of treatment $(24,26)$ and the antigen dose $(25)$ influence the durability of the treatment effect. However, the factors governing the change in clinical state remain poorly understood and require further study. These observations also underscore the importance of study design with respect to how and when the primary outcome is defined and measured.

Mechanistically, we looked for evidence of increased peanut-specific regulatory $\mathrm{T}$ cells in TS but these cell frequencies did not differ by outcome. We did observe that an overall increase in peanut-specific IgG4 during OIT was accompanied by a consistent parallel decrease in allergen-IgE binding to B cells. Both raised specific IgG4 levels and increased serum inhibitory activity were paradoxically observed in TF compared to TS. One 
explanation could be the use of pooled indicator serum rather than participants' autologous baseline serum for the IgE-FAB inhibition assay. The availability of serum was insufficient to allow for this alternative experimental design. However, we consider this explanation unlikely since in previous studies use of indicator or baseline autologous serum have yielded comparable results (27), and the data are consistent with previous studies of venom immunotherapy where these markers bore no relationship to clinical outcome. (28) During peanut OIT, in contrast to immunotherapy for respiratory allergy, (29) it is possible that IgE and/or mast cell suppression drives desensitization rather than elevated IgG4 and IgE-FAB inhibition. These findings warrant further study.

We observed a number of other interesting findings about the antibody response during OIT. In $\mathrm{TF}$, the peanut-specific IgE level amplified over the first six months of therapy, as did peanut-IgG responses (including IgG4 and other isotypes). Because TF started OIT with higher baseline peanut-IgE levels than TS, this amplification could be due to IgE-mediated facilitated antigen presentation (IgE-FAP), which has been shown to drive pathological Tcell responses in peanut-allergic but not control subjects. (30) If true, this could explain why subjects with lower IgE levels at baseline have better outcomes following OIT. The possible role of IgE-FAP in determining the response to OIT deserves further study. An important aspect of the study is that in all subjects, whether initially amplified or not, peanut-specific $\operatorname{IgE}$ was reduced to below the baseline level after a median 12 months of OIT; and this occurred proportionally in both groups to the same degree and independent of outcome (not shown). TS had lower IgE levels to peanut, Ara $\mathrm{h} 1$ and 2 at baseline and end-of-study, compared to TF, a trend observed in numerous other natural history and OIT studies. The change over time in total peanut-specific IgE was paralleled by similar changes in $\operatorname{IgE}$ specific for Ara h 1 and 2, but not Ara h 3, 8, and 9, suggesting that IgE binding to these major allergens is an important target during OIT. Although we can detect Ara $\mathrm{h} 1$ and Ara $\mathrm{h}$ 2 in the peanut flour used in this study (data not shown), in general there is little known about the relationship between major allergen dose and outcomes. This is a knowledge gap requiring further investigation.

Several single-center uncontrolled studies have previously reported on the development of sustained unresponsiveness following egg $(11,26)$ and milk $(11,25)$ OIT, but none with peanut. The only report of sustained unresponsiveness from a placebo-controlled trial of food OIT was recently published in a landmark egg OIT paper from the Consortium of Food Allergy Research. (21). This large multicenter study by Burks et al demonstrated that sustained unresponsiveness occurred in $27.5 \%$ of subjects actively treated for 22 months, compared with none in the placebo group. Successes consumed ten grams of egg-white powder and one whole egg without symptoms during a challenge four to six weeks after stopping OIT. Consistent with our observations, sustained unresponsiveness was associated with significantly smaller skin prick tests at the time of the SOFC, linking sustained mast cell suppression to a successful outcome. Importantly, no OIT study to date, including the current one, has followed a placebo control group through to the end-of-study.

Nonconsecutive enrollment, substantial subject withdrawal, and the lack of a control group are limitations in this trial, but they are common to exploratory pilot studies that carry significant and unknown risks upon inception. It is worth noting that, although there are currently many trials of peanut OIT around the world, this trial began in 2003 and was one of the first. Recruitment and retention were problematic and safety concerns were paramount.

In summary, we demonstrate for the first time that sustained unresponsiveness developed in half of peanut-allergic subjects able to complete treatment with years of OIT. Although it is not proven that this was due to OIT, it is unlikely to have occurred spontaneously. This 
change in reactivity has allowed the treatment successes to resume a diet unrestricted of peanut. Although OIT was immunomodulatory in all participants, lower peanut-IgE levels at baseline and smaller skin tests at end of study predicted successful outcomes. Larger trials with rigorous designs are warranted to further investigate the long-term effects of OIT in peanut-allergic subjects.

\section{Supplementary Material}

Refer to Web version on PubMed Central for supplementary material.

\section{Acknowledgments}

Funding Support: Food Allergy and Anaphylaxis Network, Gerber Foundation, National Institutes of Health 1R01-AI068074-01A1, Arkansas Biosciences Institute, Arkansas Children's Hospital Research Institute, Dorothy O. Robins and Family Endowment in Peanut Allergy, Food Allergy Project, Clinical and Translational Science Award 5M01-R000030-45. MH Shamji and SR Durham are part-funded by the Immune Tolerance Network, an international clinical research consortium headquartered at the University of California San Francisco and supported by the National Institute of Allergy and Infectious Diseases and the Juvenile Diabetes Research Foundation.

We thank all of the subjects and their families for volunteering to participate in this pilot project. We are grateful to the Duke Clinical Research Unit and the Pediatric Clinical Research Unit at ACH for providing an environment to conduct these studies. Xiaohong Yue, Nik Kamilaris, Huamei Zhang, and Adrienne Yancey provided invaluable laboratory assistance.

\section{Abbreviations}

$\begin{array}{ll}\text { DBPCFC } & \text { double-blinded, placebo-controlled food challenge } \\ \text { DOFC } & \text { Desensitization OFC } \\ \text { IgE } & \text { immunoglobulin E } \\ \text { LR } & \text { likelihood ratio } \\ \text { OIT } & \text { oral immunotherapy } \\ \text { OFC } & \text { Oral food challenge } \\ \text { NIH } & \text { National Institutes of Health } \\ \text { SOFC } & \text { Sustained unresponsiveness OFC } \\ \text { TF } & \text { treatment failures } \\ \text { TS } & \text { treatment successes }\end{array}$

\section{References}

1. Branum AM, Lukacs SL. Food allergy among children in the United States. Pediatrics. 2009 Dec; 124(6):1549-55. Epub 2009/11/18.eng. [PubMed: 19917585]

2. Boyce JA, Assa' ad A, Burks AW, Jones SM, Sampson HA, Wood RA, et al. Guidelines for the diagnosis and management of food allergy in the United States: report of the NIAID-sponsored expert panel. The Journal of allergy and clinical immunology. 2010 Dec; 126(6 Suppl):S1-58. Epub 2010/12/16.eng. [PubMed: 21134576]

3. Sicherer SH, Noone SA, Munoz-Furlong A. The impact of childhood food allergy on quality of life. Annals of allergy, asthma \& immunology: official publication of the American College of Allergy, Asthma, \& Immunology. 2001 Dec; 87(6):461-4. Epub 2002/01/05.eng.

4. King RM, Knibb RC, Hourihane JO. Impact of peanut allergy on quality of life, stress and anxiety in the family. Allergy. 2009 Mar; 64(3):461-8. Epub 2008/12/17.eng. [PubMed: 19076542] 
5. Bollinger ME, Dahlquist LM, Mudd K, Sonntag C, Dillinger L, McKenna K. The impact of food allergy on the daily activities of children and their families. Annals of allergy, asthma \& immunology: official publication of the American College of Allergy, Asthma, \& Immunology. 2006 Mar; 96(3):415-21. Epub 2006/04/07.eng.

6. Bock SA, Munoz-Furlong A, Sampson HA. Fatalities due to anaphylactic reactions to foods. The Journal of allergy and clinical immunology. 2001 Jan; 107(1):191-3. Epub 2001/01/10.eng. [PubMed: 11150011]

7. Bock SA, Munoz-Furlong A, Sampson HA. Further fatalities caused by anaphylactic reactions to food, 2001-2006. The Journal of allergy and clinical immunology. 2007 Apr; 119(4):1016-8. Epub 2007/02/20.eng. [PubMed: 17306354]

8. Skolnick HS, Conover-Walker MK, Koerner CB, Sampson HA, Burks W, Wood RA. The natural history of peanut allergy. The Journal of allergy and clinical immunology. 2001 Feb; 107(2):36774. Epub 2001/02/15.eng. [PubMed: 11174206]

9. Savage JH, Limb SL, Brereton NH, Wood RA. The natural history of peanut allergy: Extending our knowledge beyond childhood. The Journal of allergy and clinical immunology. 2007 Sep; 120(3): 717-9. Epub 2007/09/04.eng. [PubMed: 17765758]

10. Buchanan AD, Green TD, Jones SM, Scurlock AM, Christie L, Althage KA, et al. Egg oral immunotherapy in nonanaphylactic children with egg allergy. The Journal of allergy and clinical immunology. 2007 Jan; 119(1):199-205. Epub 2007/01/09.eng. [PubMed: 17208602]

11. Staden U, Rolinck-Werninghaus C, Brewe F, Wahn U, Niggemann B, Beyer K. Specific oral tolerance induction in food allergy in children: efficacy and clinical patterns of reaction. Allergy. 2007 Nov; 62(11):1261-9. Epub 2007/10/09.eng. [PubMed: 17919140]

12. Skripak JM, Nash SD, Rowley H, Brereton NH, Oh S, Hamilton RG, et al. A randomized, doubleblind, placebo-controlled study of milk oral immunotherapy for cow's milk allergy. The Journal of allergy and clinical immunology. 2008 Dec; 122(6):1154-60. Epub 2008/10/28.eng. [PubMed: 18951617]

13. Jones SM, Pons L, Roberts JL, Scurlock AM, Perry TT, Kulis M, et al. Clinical efficacy and immune regulation with peanut oral immunotherapy. The Journal of allergy and clinical immunology. 2009 Aug; 124(2):292-300. e1-97. Epub 2009/07/07.eng. [PubMed: 19577283]

14. Blumchen K, Ulbricht H, Staden U, Dobberstein K, Beschorner J, de Oliveira LC, et al. Oral peanut immunotherapy in children with peanut anaphylaxis. The Journal of allergy and clinical immunology. 2010 Jul; 126(1):83-91. e1. Epub 2010/06/15.eng. [PubMed: 20542324]

15. Varshney P, Jones SM, Scurlock AM, Perry TT, Kemper A, Steele P, et al. A randomized controlled study of peanut oral immunotherapy: clinical desensitization and modulation of the allergic response. The Journal of allergy and clinical immunology. 2011 Mar; 127(3):654-60. Epub 2011/03/08.eng. [PubMed: 21377034]

16. Vickery BP, Lin J, Kulis M, Fu Z, Steele PH, Jones SM, et al. Peanut oral immunotherapy modifies IgE and IgG4 responses to major peanut allergens. The Journal of allergy and clinical immunology. 2013 Jan; 131(1):128-34. e1-3. Epub 2012/12/04.eng. [PubMed: 23199605]

17. Thyagarajan A, Jones SM, Calatroni A, Pons L, Kulis M, Woo CS, et al. Evidence of pathwayspecific basophil anergy induced by peanut oral immunotherapy in peanut-allergic children. Clinical and experimental allergy: journal of the British Society for Allergy and Clinical Immunology. 2012 Aug; 42(8):1197-205. Epub 2012/07/19.eng. [PubMed: 22805467]

18. Durham SR, Emminger W, Kapp A, de Monchy JG, Rak S, Scadding GK, et al. SQ-standardized sublingual grass immunotherapy: confirmation of disease modification 2 years after 3 years of treatment in a randomized trial. The Journal of allergy and clinical immunology. 2012 Mar; 129(3):717-25. e5. Epub 2012/01/31.eng. [PubMed: 22285278]

19. Durham SR, Walker SM, Varga EM, Jacobson MR, O'Brien F, Noble W, et al. Long-term clinical efficacy of grass-pollen immunotherapy. The New England journal of medicine. 1999 Aug 12; 341(7):468-75. Epub 1999/08/12.eng. [PubMed: 10441602]

20. Golden DB, Kagey-Sobotka A, Norman PS, Hamilton RG, Lichtenstein LM. Outcomes of allergy to insect stings in children, with and without venom immunotherapy. The New England journal of medicine. 2004 Aug 12; 351(7):668-74. Epub 2004/08/13.eng. [PubMed: 15306668] 
21. Burks AW, Jones SM, Wood RA, Fleischer DM, Sicherer SH, Lindblad RW, et al. Oral immunotherapy for treatment of egg allergy in children. The New England journal of medicine. 2012 Jul 19; 367(3):233-43. Epub 2012/07/20.eng. [PubMed: 22808958]

22. Neuman-Sunshine DL, Eckman JA, Keet CA, Matsui EC, Peng RD, Lenehan PJ, et al. The natural history of persistent peanut allergy. Annals of allergy, asthma \& immunology: official publication of the American College of Allergy, Asthma, \& Immunology. 2012 May; 108(5):326-31. e3. Epub 2012/05/01.eng.

23. Keet CA, Seopaul S, Knorr S, Narisety S, Skripak J, Wood RA. Long-term follow-up of oral immunotherapy for cow's milk allergy. The Journal of allergy and clinical immunology. 2013 Jun 25. Epub 2013/06/29.eng.

24. Narisety SD, Wood RA. Forecast for food allergen immunotherapy: partly desensitized or a chance of cure? Expert review of clinical immunology. 2010 Mar; 6(2):177-9. Epub 2010/04/21.eng. [PubMed: 20402377]

25. Keet CA, Frischmeyer-Guerrerio PA, Thyagarajan A, Schroeder JT, Hamilton RG, Boden S, et al. The safety and efficacy of sublingual and oral immunotherapy for milk allergy. The Journal of allergy and clinical immunology. 2012 Feb; 129(2):448-55. e1-5. Epub 2011/12/02.eng. [PubMed: 22130425]

26. Vickery BP, Pons L, Kulis M, Steele P, Jones SM, Burks AW. Individualized IgE-based dosing of egg oral immunotherapy and the development of tolerance. Annals of allergy, asthma \& immunology: official publication of the American College of Allergy, Asthma, \& Immunology. 2010 Dec; 105(6):444-50. Epub 2010/12/07.eng.

27. Würtzen PA, Lund G, Lund K, Arvidsson M, Rak S, Ipsen H. A double-blind placebo-controlled birch allergy vaccination study II: correlation between inhibition of IgE binding, histamine release and facilitated allergen presentation. Clin Exp Allergy. 2008 Aug; 38(8):1290-301. [PubMed: 18510696]

28. Varga EM, Francis JN, Zach MS, Klunker S, Aberer W, Durham SR. Time course of serum inhibitory activity for facilitated allergen-IgE binding during bee venom immunotherapy in children. Clinical and experimental allergy: journal of the British Society for Allergy and Clinical Immunology. 2009 Sep; 39(9):1353-7. Epub 2009/06/23.eng. [PubMed: 19538349]

29. James LK, Shamji MH, Walker SM, Wilson DR, Wachholz PA, Francis JN, et al. Long-term tolerance after allergen immunotherapy is accompanied by selective persistence of blocking antibodies. The Journal of allergy and clinical immunology. 2011 Feb; 127(2):509-16. e1-5. Epub 2011/02/02.eng. [PubMed: 21281875]

30. Turcanu V, Stephens AC, Chan SM, Rance F, Lack G. IgE-mediated facilitated antigen presentation underlies higher immune responses in peanut allergy. Allergy. 2010 Oct; 65(10): 1274-81. Epub 2010/04/14.eng. [PubMed: 20384616] 


\section{Key Messages}

- Half of peanut-allergic subjects completing this pilot study of peanut OIT consumed $5000 \mathrm{mg}$ of peanut protein and an open oral feeding of peanut butter one month after stopping treatment.

- It is not known if this change is permanent, but most of these subjects are consuming peanuts in their diet.

- These subjects started and ended the study with less peanut- and Ara h 1- and Ara $\mathrm{h}$ 2- specific IgE, smaller skin tests, lower peanut-specific:total IgE ratios, and similar IgG4 levels compared to those unable to pass the final challenge. 


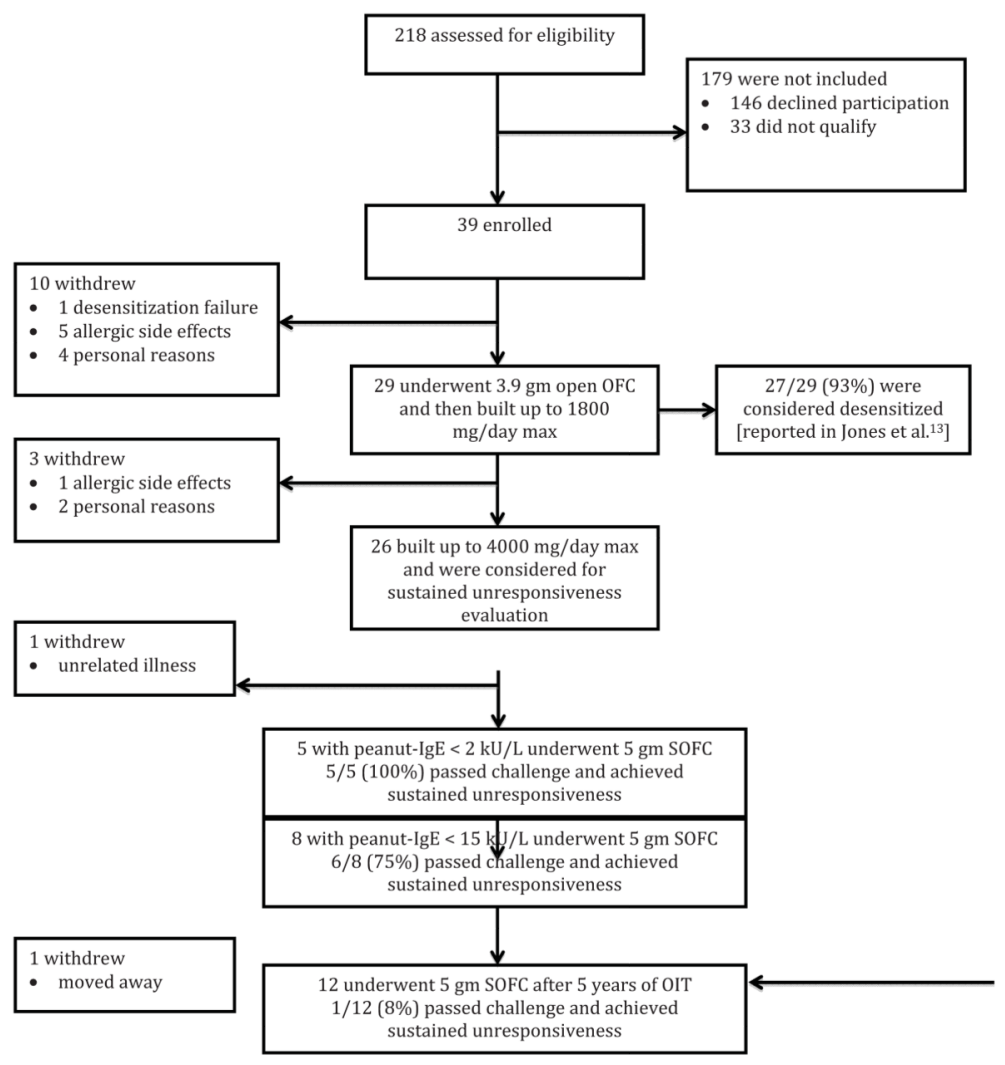

Figure 1.

Conduct of the study.

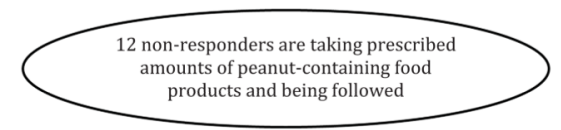




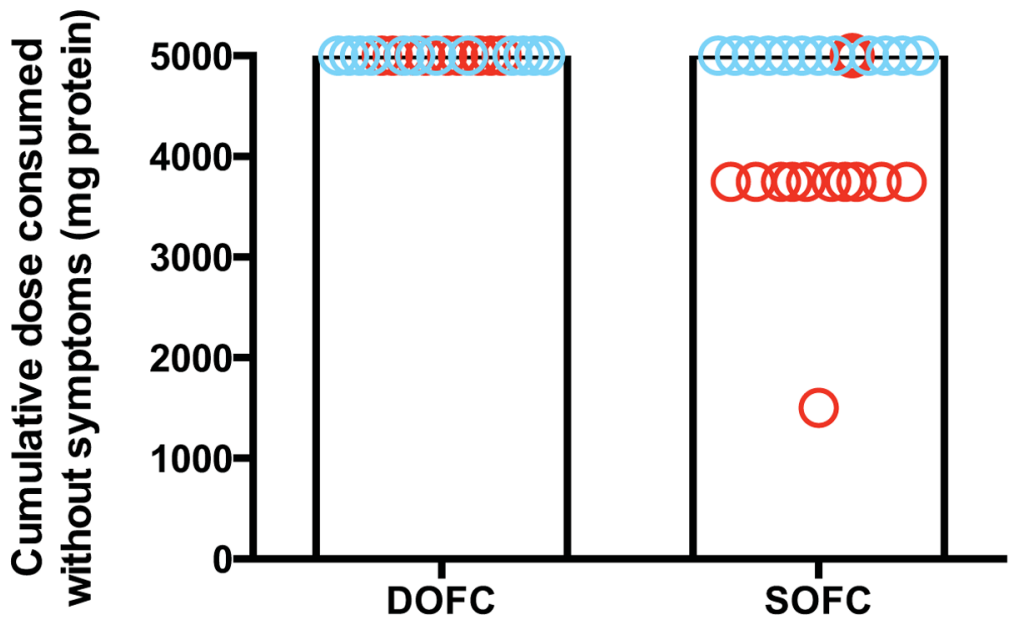

\section{Treatment Successes (TS)} Treatment Failures (TF)

Figure 2.

Food challenge results. Shown are the cumulative amounts of protein successfully ingested prior to the onset of symptoms in TS (blue) and TF (red) circles. Each circle represents one subject. 
A

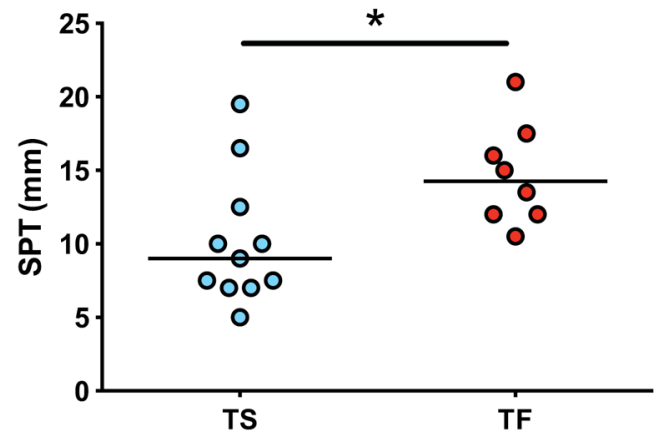

B
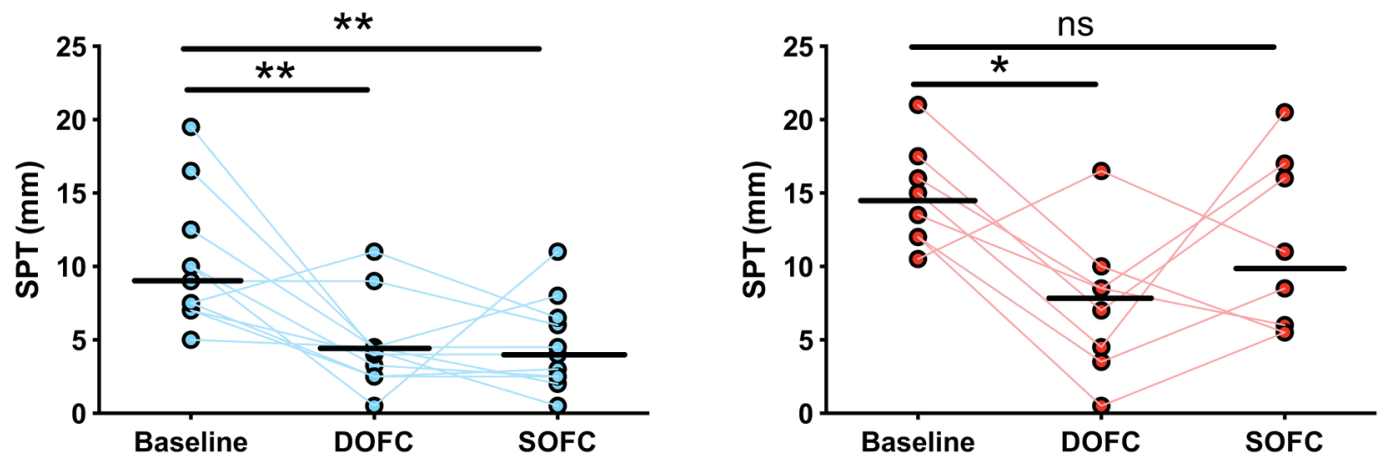

Figure 3.

Skin prick test results. (A) Average mean wheal diameters at baseline are shown, by outcome. (B) Mean wheal diameters over time, by outcome. Lines represent median values. $* \mathrm{p}<0.05 ; * * \mathrm{p}<0.01 ; * * * \mathrm{p}<0.001$ 
A

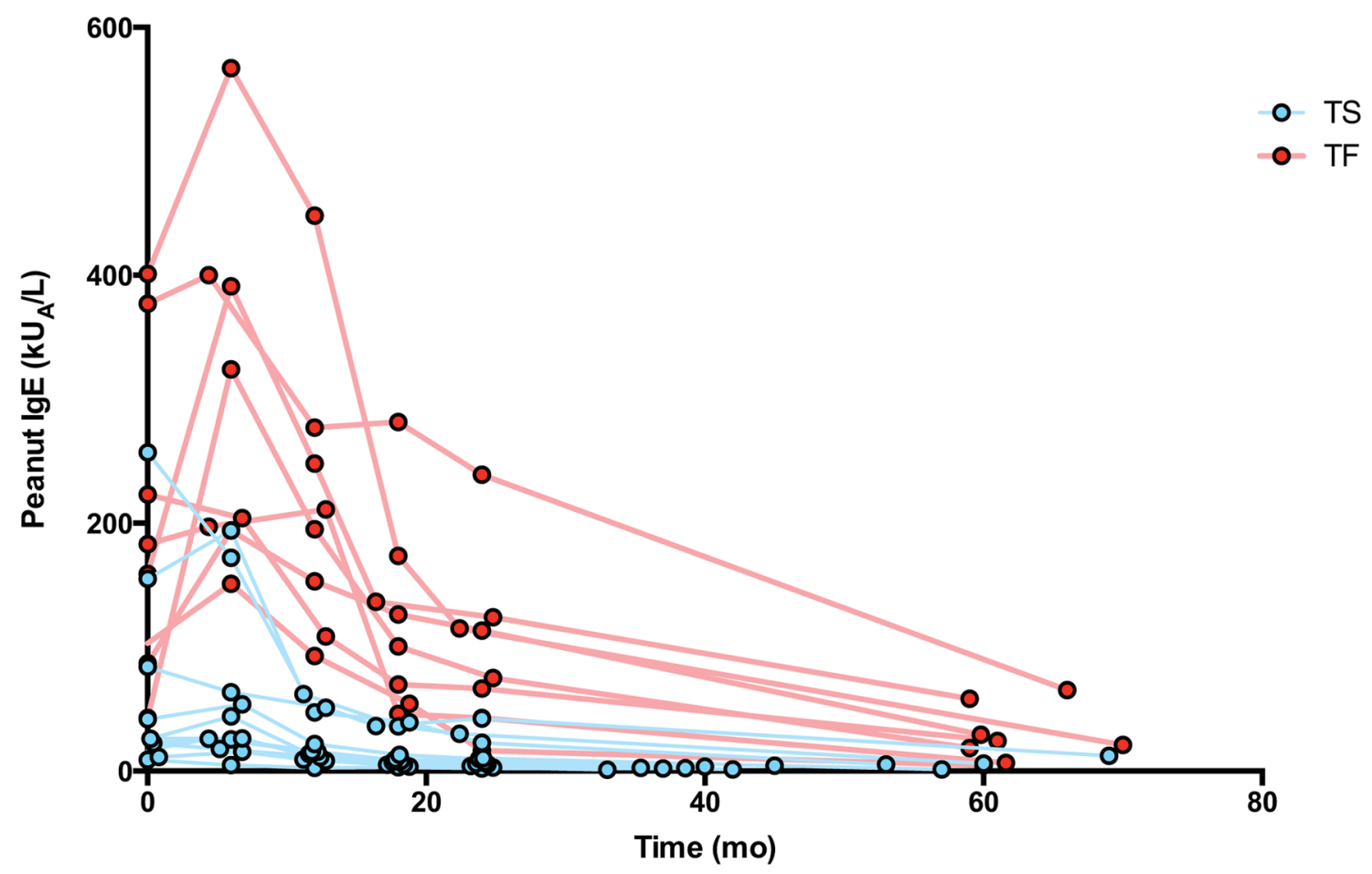

B
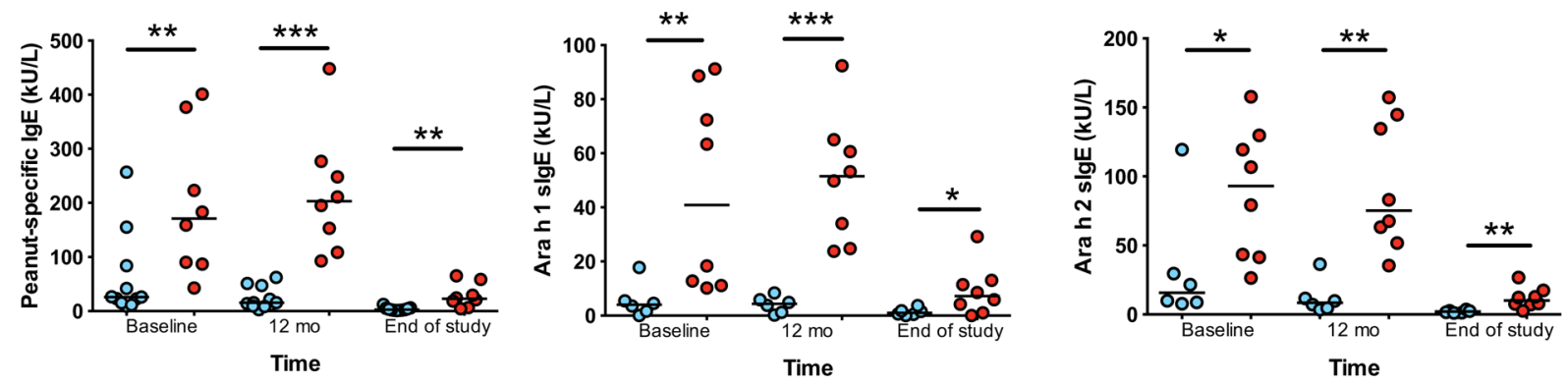

C

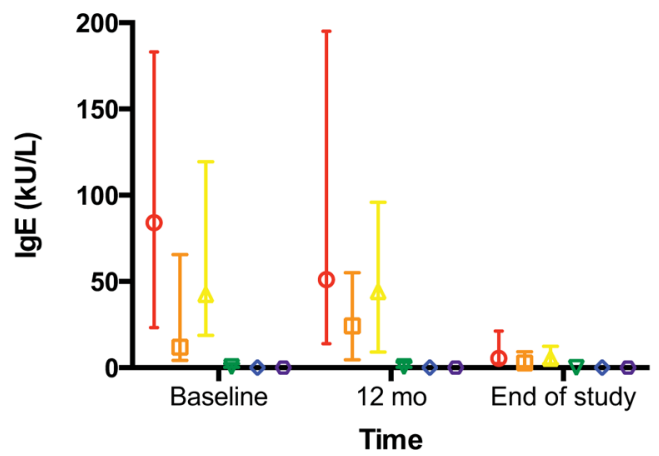

○ Peanut

a Arah 1

Ara h 2

$\nabla$ Arah 3

$\diamond$ Arah 8

- Arah 9 

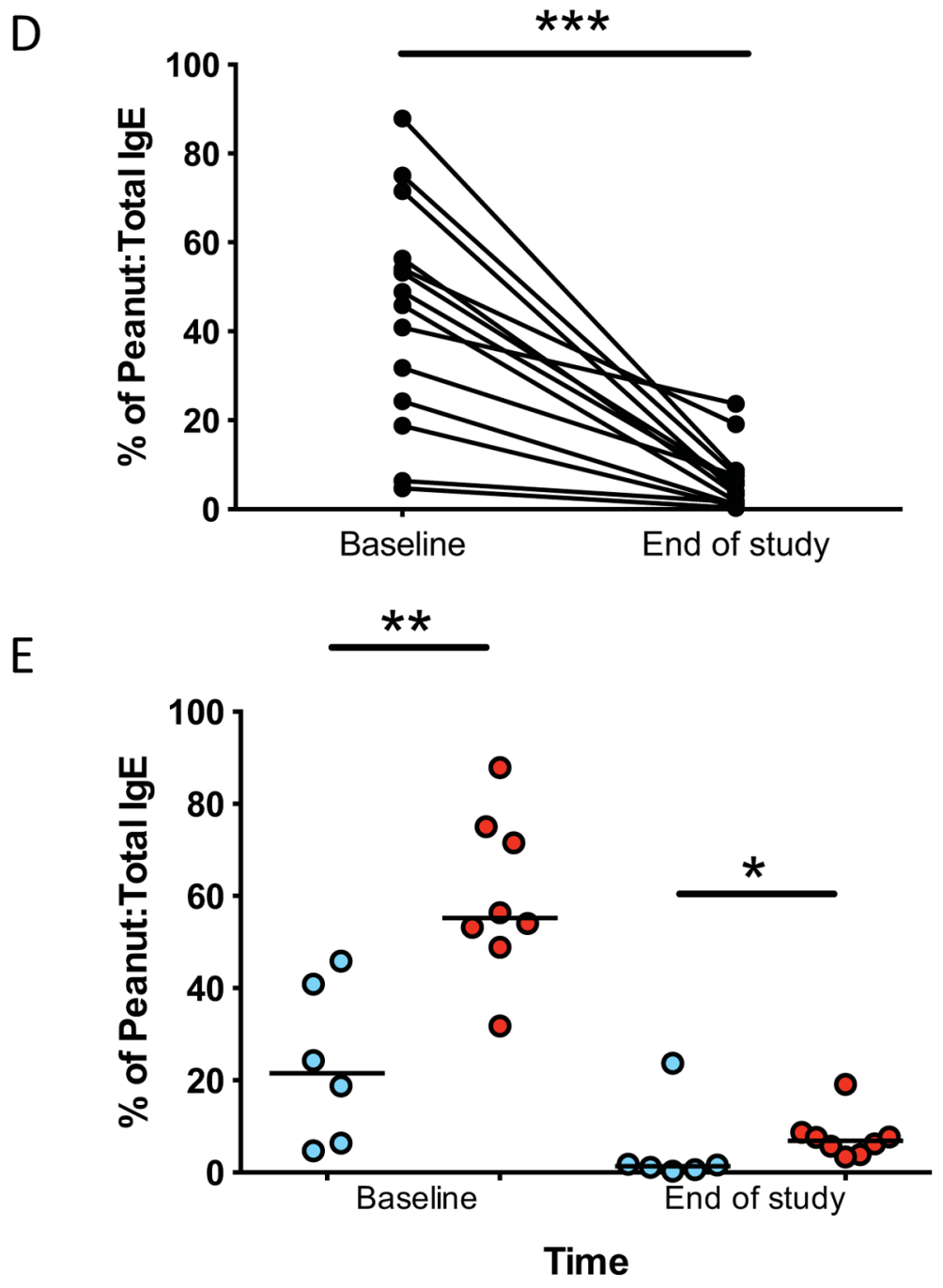

Figure 4.

Peanut- and component-specific serum IgE during OIT. Longitudinal peanut- (A), and Ara h 1-, and Ara h 2-specific (B) IgE are shown for individual subjects by outcome, and for all components in all subjects (C). Peanut-specific IgE to total $\operatorname{IgE}$ ratio is shown for all subjects (D) and for individual subjects by outcome (E). All point estimates are medians, with interquartile range $(\mathrm{C}) . * \mathrm{p}<0.05 ; * * \mathrm{p}<0.01 ; * * * \mathrm{p}<0.001$. 


\section{A}

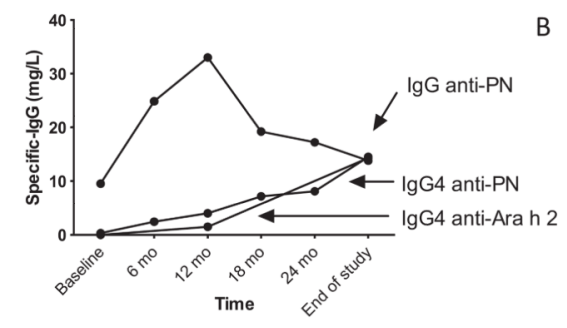

c

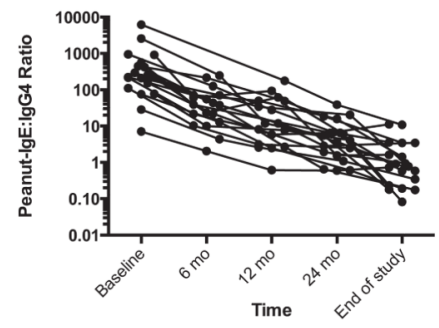

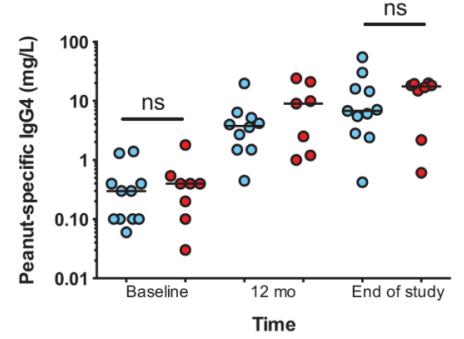

D

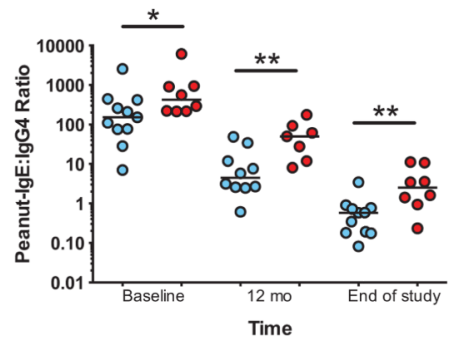

Figure 5.

Peanut-specific serum IgG, IgG4, and IgE/IgG4 ratios during OIT. Median values for all subjects' longitudinal peanut-specific $\operatorname{IgG}$ and $\operatorname{IgG} 4$, and Ara h 2-specific $\operatorname{IgG} 4$ are shown (A). Peanut-specific IgG4 (B) are shown for individual by outcome. Peanut-specific IgE/ IgG4 ratios are shown for all subjects (C), and by outcome (D). Lines representing medians. $* \mathrm{p}<0.05 ; * * \mathrm{p}<0.01$ 
A

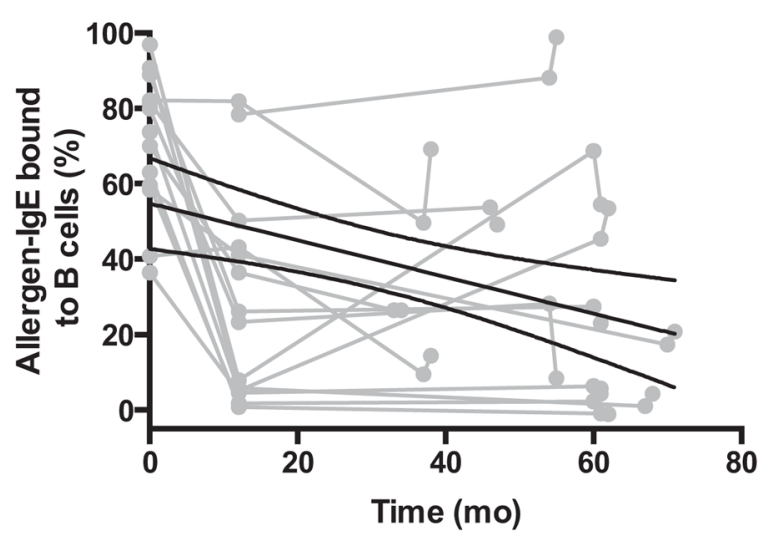

B

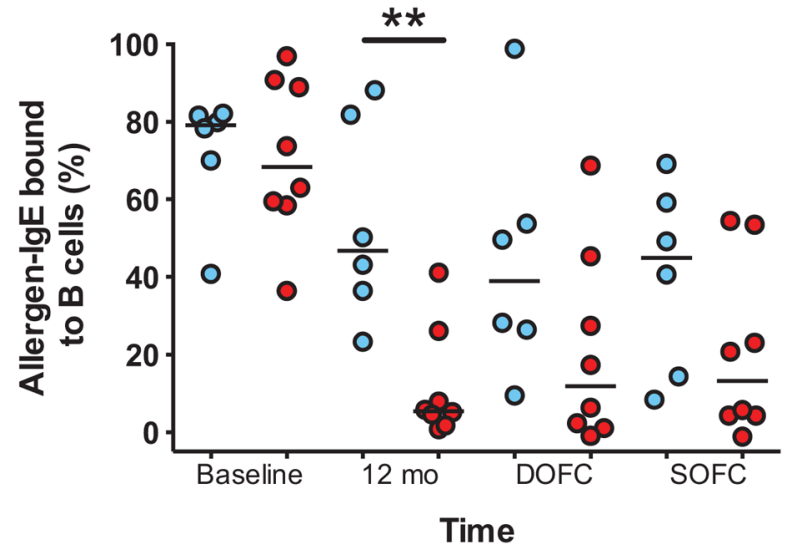

Figure 6.

Serum from subjects on peanut OIT inhibits facilitated antigen binding (FAB). FAB data are shown for all individual subjects in grey, with mean linear regression slope coefficient (black line) and 95\%CI (hatched line)(A). FAB by outcome, with lines representing medians (B). $* * \mathrm{p}<0.01$. 